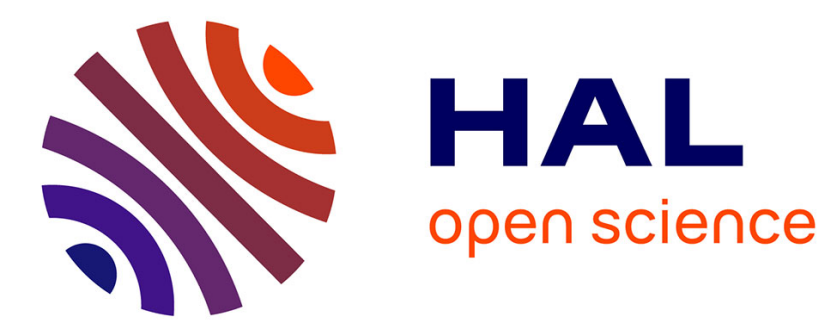

\title{
Interaction between Cr-bearing pigments and transparent glaze: A transmission electron microscopy study
}

Louisiane Verger, Olivier Dargaud, Nicolas Menguy, David Troadec, Laurent Cormier

\section{To cite this version:}

Louisiane Verger, Olivier Dargaud, Nicolas Menguy, David Troadec, Laurent Cormier. Interaction between Cr-bearing pigments and transparent glaze: A transmission electron microscopy study. Journal of Non-Crystalline Solids, 2017, 459, pp.184 - 191. 10.1016/j.jnoncrysol.2017.01.016 . hal-01458161

\section{HAL Id: hal-01458161 https://hal.sorbonne-universite.fr/hal-01458161}

Submitted on 6 Feb 2017

HAL is a multi-disciplinary open access archive for the deposit and dissemination of scientific research documents, whether they are published or not. The documents may come from teaching and research institutions in France or abroad, or from public or private research centers.
L'archive ouverte pluridisciplinaire HAL, est destinée au dépôt et à la diffusion de documents scientifiques de niveau recherche, publiés ou non, émanant des établissements d'enseignement et de recherche français ou étrangers, des laboratoires publics ou privés. 
Interaction between Cr-bearing pigments and transparent glaze: a transmission electron microscopy study

Louisiane Verger ${ }^{1,2}$ Olivier Dargaud, ${ }^{2}$ Nicolas Menguy, ${ }^{1}$ David Troadec, ${ }^{3}$ Laurent Cormier ${ }^{1}$

1. Institut de Minéralogie, de Physique des Matériaux et de Cosmochimie (IMPMC), Sorbonne Universités, UPMC Univ Paris 06, CNRS UMR 7590, Museum National d'Histoire Naturelle, IRD UMR 206, 4 place Jussieu, F-75005 Paris, France

2. Cité de la céramique - Sèvres et Limoges, 2 Place de la Manufacture, 92310 Sèvres, France

3. Institut d'électronique de microélectronique et de nanotechnologie (IEMN), UMR CNRS 8520, ISEN Department, 59046 Lille, France

\begin{abstract}
:
Spinel $\mathrm{ZnAl}_{2} \mathrm{O}_{4}$ and corundum $\mathrm{Al}_{2} \mathrm{O}_{3}$ doped with chromium are used as pink pigments in porcelain glazes. However, alteration of the color can occur during firing, and the resulting glaze appears brown and green respectively, instead of the expected pink. To investigate the mechanism of color change, electron transparent sections were prepared by Focused Ion Beam (FIB) at the interface between pigment and glaze. Observations under a transmission electron microscope (TEM) reveal a common mechanism for both systems. Al migration from the pigment toward the silicate melt results in alteration of the grain of pigments, and
\end{abstract}


formation of a $\mathrm{Cr}$ enriched phase, with the same crystalline structure than the initial pigment. Furthermore, the formation of anorthite is reported, due to the increase of the local concentration of $\mathrm{Al}$ in the melt. The different morphologies of altered grains of pigment encountered in the glaze are discussed base on the TEM observations.

Keywords: electron microscopy, pigments, glaze, color alteration, chromium oxides

\section{Introduction}

The stability of chromium-bearing crystals in glasses, slags or melts has been the subject of several studies. The dissolution/crystallization behavior is an important process to understand aggressive attack of refractory materials by molten metallurgical slags and melts [1], crystal/melt partition in igneous processes $[2,3]$ or the possibility of high chromium loading in nuclear glass wastes [4]. Chromium is also used in glaze coatings, painted tiles or porcelain stonewares as sub-microcrystallites that can influence the color or macrocrystallites for aesthetic ornaments (crystalline glazes) [5-7]. Though chromium was isolated only in 1797 by Nicolas Louis Vauquelin in France [8], it was rapidly used to color ceramics, especially at the French Manufacture of Sèvres (Sèvres factory of porcelains) under the leadership of its director Alexandre Brongniart, a former collaborator of Vauquelin [9]. Indeed Cr-bearing crystals produce a richness of colors that was not available before the discovery of this element. A wide range of Cr-bearing pigments was developed yielding to various colorations: pink, red, reddish brown or green [10]. To obtain a glaze, the crystalline pigments are dispersed in a uncolored frit and after firing, the color of the crystal is imparted to the glaze.

The color property strongly depends on the nature of crystal structure incorporating chromium, but it is also altered by possible reactions during firing between the starting 
pigment and the corrosive silicate melts, i.e. the glazes and frits, as noticed in previous investigations $[5-7,11-16]$. These works conclude that reactions during firing are most likely due to the dissolution of pigment through chemical attacks. However, the main challenge is still to understand the possible interactions occurring between pigments and ceramic-matrices resulting in a color change after firing.

Previous works were essentially focused on the color change of iron-chromium pigments composed of $(\mathrm{Cr}, \mathrm{Fe})_{2} \mathrm{O}_{3}$ in zinc-based and zinc-free glazes $[6,7,11,12,14]$. They reveal the importance of the glass matrix composition, the outward diffusion of Fe into the glaze, and the formation of spinel $(\mathrm{Zn}, \mathrm{Fe})(\mathrm{Cr}, \mathrm{Fe})_{2} \mathrm{O}_{4}$ in zinc-based glazes. For the malayaite pink pigments $\left(\mathrm{CaSnSiO}_{5}: \mathrm{Cr}\right)$ used in different glazes, a drastic change of the color also occurs towards paler shades or in the appearance of a bluish hue, attributed to the formation of $\mathrm{BaSnSi}_{3} \mathrm{O}_{9}[15,17]$.

At the Sèvres factory, almost $60 \%$ of pigments composed of chromium oxides are spinels, synthesized in its laboratory. However, they undergo a change of color in a commonly used uncolored frit. It is a mixture of feldspar, kaolin, quartz and chalk (in proportion specific to Sèvres' porcelain) that vitrifies during the firing process. In this particular decoration, the pink color of spinel and corundum doped with chromium pigments is not stable: the resulting spinel and corundum glazes appear respectively brown and green.

In our previous investigation on a spinel pigment mainly composed of $\mathrm{ZnAl}_{1.59} \mathrm{Cr}_{0.41} \mathrm{O}_{4}$ $[16,18]$, we showed that the color change is caused by a modification of the $\mathrm{Cr}$ content in the spinel phase. It was evidenced that the initial pigment $\mathrm{ZnAl}_{1.59} \mathrm{Cr}_{0.41} \mathrm{O}_{4}$ gradually dissolves in favor of a Cr-enriched phase $\mathrm{ZnAl}_{0.54} \mathrm{Cr}_{1.46} \mathrm{O}_{4}$.

This behavior is somewhat related to the peraluminosity of the frit/glaze defined as:

$R=n_{\mathrm{Al} 2 \mathrm{O} 3} /\left(n_{\mathrm{Na} 2 \mathrm{O}}+n_{\mathrm{MgO}}+n_{\mathrm{K} 2 \mathrm{O}}+n_{\mathrm{CaO}}\right)$ 
with $n_{\mathrm{Al2O}}$ and $\left(n_{\mathrm{Na2O}}+n_{\mathrm{MgO}}+n_{\mathrm{K} 2 \mathrm{O}}+n_{\mathrm{CaO}}\right)$ the molar content in alumina and alkali and alkaline-earth oxides in the specimen, respectively. When $\mathrm{R}<1$, the glass is peralkaline and when $\mathrm{R}>1$, the glass is peraluminous. The starting frit has a low peraluminosity of 0.50 . When $\mathrm{Al}_{2} \mathrm{O}_{3}$ content is increased in the uncolored frit, i.e. the peraluminosity increases, the dissolution of the pigment was found to be reduced. It was conclude that the enrichment in $\mathrm{Cr}$ of the spinel after firing results from the gradual migration of $\mathrm{Al}$ from the pigment to the glaze, without changing the nature of the crystalline phase.

The color change occurring with corundum doped with chromium pigment was also observed by Martos et al. [5] It was found that the presence of $\mathrm{ZnO}$ was required for stabilizing the pink coloration in the glaze. However, the mechanism that underlies this change of color is still not known.

In this paper we will examine several examples of interaction between chromium pink pigments and the frit glass matrix. We will focus on the Al diffusion by analyzing the interface between the pigment and the surrounding glass. Focused Ion Beam (FIB) crosssection are used for analyses by transmission electron microscope (TEM), revealing a common dissolution mechanism and reaction at the pigment/glaze interface for Cr-doped spinel and corundum pigments.

\section{Materials and methods}

Two pigments containing $\mathrm{Cr}$ were selected for this study. They are historically synthesized at the Sèvres factory and named 10045 and 10059. Pigment 10045 is mainly composed of a spinel phase $\mathrm{ZnAl}_{1.59} \mathrm{Cr}_{0.41} \mathrm{O}_{4}$, characterized in our previous investigation[16]. Pigment 10059 is composed of a corundum phase, $\mathrm{Al}_{1.9} \mathrm{Cr}_{0.1} \mathrm{O}_{3}$. Its composition was determined by Rietveld refinement, using the linear regression from Rossi et al.[19] that relates the cell parameters $(a$ 
and $c$ ) to the $\mathrm{Cr}$ concentration $x$ in $\mathrm{Al}_{2-\mathrm{x}} \mathrm{Cr}_{\mathrm{x}} \mathrm{O}_{3}$ following Vegard's law. Glazes are obtained by mixing $0.5 \mathrm{~g}$ of pigment with $4.5 \mathrm{~g}$ of an uncolored crystallized frit named CI. The frit is composed of feldspar, kaolin, quartz and chalk in proportions specific to the porcelain of Sèvres. The mixture was not ground in order to observe larger grains of pigment and characterize the interface between the crystal and the uncolored glass. The mixture of the pigment and the frit is painted on a round porcelain mount, which is then fired. The heat treatment is the one used for firing porcelain artifacts at the manufacture: $1000^{\circ} \mathrm{C}$ is reached in ten hours, then $1280^{\circ} \mathrm{C}$ is reached in $5 \mathrm{~h} 30$. Once $1280^{\circ} \mathrm{C}$ is reached, the oven is immediately turned off and slowly cooled down to room temperature. The atmosphere of the oven is not controlled for the preparation of this kind of decoration. Glazes composed of pigment 10045 and pigment 10059 are respectively called g-spinel and g-corundum.

Cross sections were cut from the porcelain shard with the glaze on the top. The fragment was embedded in a resin block, polished using diamond pastes down to $3 \mu \mathrm{m}$ and carbon coated. Scanning Electron Microscopy (SEM) analyses were carried out with a Zeiss Ultra55, using an acceleration voltage of $15 \mathrm{kV}$, a working distance of $7.5 \mathrm{~mm}$ and a backscattered electrons detector, associated to an X-ray Energy Dispersive Spectroscopy (XEDS) microprobe. Electron transparent foils were prepared using Focused Ion Beam (FIB) on a FEI STRATA DB235 instrument. Sections were analyzed with a JEOL 2100F microscope operating at 200 $\mathrm{kV}$. This microscope was equipped with a field emission gun, an ultra-high resolution (UHR) pole piece and a scanning TEM (STEM) device, which allowed Z-contrast imaging in the high angle annular dark field (STEM-HAADF) mode. Chemical analyses were performed using a JEOL detector with an ultrathin window by XEDS elemental mapping in the STEMXEDS mode. Selecting area electron diffraction (SAED) patterns were acquired along two or three zone axis to identify unambiguously the structure of the crystal (only one axis is shown in figures). 
X-ray diffraction (XRD) pattern of g-corundum was collected directly on the glaze without specific preparation, using a PANalytical X'Pert PRO diffractometer with $\mathrm{Cu} \mathrm{K} \alpha$ radiations $\left(\lambda_{\mathrm{Cu}, \mathrm{Ka} 1}=1.54056 \AA, \lambda_{\mathrm{Cu}, \mathrm{Ka} 2}=1.54439 \AA\right)$ operating under $40 \mathrm{kV}$ and $40 \mathrm{~mA}$, in the $10^{\circ} 2 \theta$ to $130^{\circ} 2 \theta$ range, with $0.0167^{\circ} 2 \theta$ steps and a counting time of $550 \mathrm{~s}$ per step.

\section{Results}

\subsection{Morphological aspect of the spinel pigment grains in the glaze}

The g-spinel glaze is composed of crystalline grains embedded in a glass that results from the melting of the uncolored frit. The grains correspond to the initial pigment, partially altered by reactions with the silicate melt during the heat treatment [16]. We previously showed that the initial pigment has the spinel phase composition $\mathrm{ZnAl}_{1.59} \mathrm{Cr}_{0.41} \mathrm{O}_{4}$ (spinel-Cr0.41). This pigment is not stable during firing, leading to the formation of a Cr-enriched spinel $\mathrm{ZnAl}_{0.54} \mathrm{Cr}_{1.46} \mathrm{O}_{4}$ (spinel-Cr1.46) [16]. Three grain populations in the same glaze can be distinguished. Fig. 1a shows homogeneous aggregated grains composed of spinel-Cr1.46. Their diameter is typically below $1 \mu \mathrm{m}$. Their chemical composition (determined by SEM analysis associated with EDX measurements) indicates that those grains results from complete alteration of the initial phase that is not observed. Fig. $1 \mathrm{~b}$ shows grains that are partially altered: the center has the composition of the initial spinel-Cr0.41 while the periphery corresponds to the spinel-Cr1.46. Their size is typically around $10 \mu \mathrm{m}$. The third example (Fig. 1c) shows also the presence of the initial pigment spinel-Cr0.41 and the new phase spinel-Cr1.46, but additional phases pointed out by arrows are present. It seems to diffuse from the pigment grain to the glass. From the backscattered electron imaging contrast of Fig. 1c, this phase seems to be devoid of $\mathrm{Cr}$ and $\mathrm{Zn}$ and is observed around grains of large size (> $15 \mu \mathrm{m})$ and on aggregate of grains. 
The change in the composition of spinel is at the origin of the color change between the initial pigment (pink) and the glaze (brown), in agreement with a colorimetric analysis of the spinel solid solution $\mathrm{ZnAl}_{2-\mathrm{x}} \mathrm{Cr}_{\mathrm{x}} \mathrm{O}_{4}$ [18].

\subsection{Interface between spinel grain and the glass}

In order to get more information on $(i)$ possible crystallographic relationship between the two spinel phases (i.e. the parent spinel-Cr0.41 and the new phase spinel-Cr1.46) and (ii) to investigate the crystalline nature of the additional phase, a TEM thin foil was obtained using FIB method from an area exhibiting all the phases aforementioned.

Fig. 2a-e corresponds to STEM-XEDS elemental mapping achieved using Si-K $\alpha, \mathrm{Al}-\mathrm{K} \alpha, \mathrm{Ca}-$ $\mathrm{K} \alpha, \mathrm{Cr}-\mathrm{K} \alpha, \mathrm{Zn}-\mathrm{K} \alpha$ lines. As shown on the composite image (Fig. 2f), four different phases can be distinguished from the compositional criterion. Areas appearing in orange and green in Fig. $2 \mathrm{f}$ are related to the spinel phases previously observed by SEM: the undissolved initial pigment (spinel-Cr0.41) rich in $\mathrm{Al}$ and $\mathrm{Zn}$ (Fig. 2b,e) correspond to the orange zone and is surrounded by smaller grains of spinel-Cr1.46 rich in $\mathrm{Cr}$ and $\mathrm{Zn}$ (Fig. 2d,e) that coincide with green areas. SAED patterns acquired on initial pigment (Fig. 3b) and grains of spinel-Cr1.46 (Fig. 3c) confirm that the grains have the spinel structure. Moreover, SAED patterns indicate also that both Al-rich and Cr-rich crystals are orientated along almost the same direction suggesting a possible solid state transformation i.e. without a dissolution - reprecipitation process. From STEM-XEDS elemental mapping (Fig. 2a) and SAED observations (data not shown), areas appearing in blue in Fig. $2 \mathrm{f}$ and Fig. 3a correspond to amorphous $\mathrm{SiO}_{2}$-rich phase resulting from the vitrification of the uncolored frit. Finally, magenta areas in Fig. $2 f$ and Fig. 3a are related to phases spreading out from the grain of pigment to the glass (they are only observed at close proximity of the initial grain pigment). The chemical composition 
deduced from XEDS measurements and SAED analysis (Fig. 4c) strongly suggests the presence of anorthite $\mathrm{CaAl}_{2} \mathrm{Si}_{2} \mathrm{O}_{8}$. This corresponds to the meta-aluminosilicate join, i.e. a peraluminosity of 1. HREM images (Fig. 4d) acquired on these phases reveal the presence of planar stacking fault and (010) twinning planes typical for anorthite, as reported by Xu et al. $[20]$.

\subsection{Interface between the $\mathrm{Al}_{2} \mathrm{O}_{3}: \mathrm{Cr}^{3+}$ corundum pigment and the glass}

In order to investigate the impact of the crystalline structure of the pigment on its reactivity, pigment 10059 composed of corundum $\mathrm{Al}_{1.9} \mathrm{Cr}_{0.1} \mathrm{O}_{3}$ was studied. The pink color of the pigment is modified during firing, and the glaze presents a green hue. Contrary to pigment 10045, no further crystalline phase composed of chromium was detected by XRD in the glaze. However, the formation of anorthite with trace of sodium is detected by XRD on this sample (Fig. 5).

SEM observations on a cross section of the glaze was particularly challenging because the contrast between the grains of pigment and the glassy matrix was not good enough from the different images (secondary or backscattered electrons) to distinguish them. Grains of pigments can only be identified from XEDS elemental mapping of Al. Heterogeneity in $\mathrm{Cr}$ concentration was observed on XEDS mapping, but the spatial resolution was not sufficient enough to relate them to a crystalline phase. Therefore, in order to understand the mechanism of color change in this case, a TEM analysis was carried out on a thin foil prepared using the FIB method at the interface between a grain of pigment and the glass. From XEDS elemental maps and SAED analyses shown on Fig. 6, four main areas can be distinguished, similarly to the g-spinel glaze. 
The orange area seen on the elemental composite image (Fig. 6f) corresponds to a crystalline phase with a corundum structure whose chemical composition determined by XEDS analysis, and despite small variations on the Cr-content (Fig. 6d), is close to the one of the initial pigment $\mathrm{Al}_{1.9} \mathrm{Cr}_{0.1} \mathrm{O}_{3}$. From SAED patterns (only one zone axis is shown in Fig. $6 \mathrm{~g}$ ) acquired in different areas of this phase, it appears that all the sub-grains have the same orientation with very minor deviations. From these observations, it can be inferred that this area corresponds to an unaltered grain of the initial pigment. The Cr-bearing corundum crystal is surrounded by a Ca-rich crystalline phase (Fig. 6c) that is shown to be anorthite from SAED pattern (Fig. 6h) and XEDS measurements of the composition. Si- and K-rich area labeled $(i)$ on Fig. $5 \mathrm{f}$ corresponds to the glass resulting from the vitrification of the uncolored frit.

At the periphery of the $\mathrm{Al}_{1.9} \mathrm{Cr}_{0.1} \mathrm{O}_{3}$ crystal, small Cr-rich crystals are present and are visible on the STEM-HAADF image presented on Fig. 7a. As shown on Fig. 7b, their size is around $50 \mathrm{~nm} \times 50 \mathrm{~nm}$ and they are dispersed in the anorthite phase closely to the $\mathrm{Al}_{1.9} \mathrm{Cr}_{0.1} \mathrm{O}_{3}$ crystal. From HREM observations and subsequent Fourier transform analysis (Fig. 7c,d), it can be concluded that these crystals exhibit the corundum structure as well, which indicates that they are grains of eskolaite $\mathrm{Cr}_{2} \mathrm{O}_{3}$. Their presence reveals that the $\mathrm{Al}_{1.9} \mathrm{Cr}_{0.1} \mathrm{O}_{3}$ initial grain of pigment reacts during firing, leading to the formation of $\mathrm{Cr}_{2} \mathrm{O}_{3}$. Eskolaite $\mathrm{Cr}_{2} \mathrm{O}_{3}$ is green, thereby its formation explains the color change between the pigment (pink) and the glaze (green). Contrary to g-spinel, the size and quantity of chromium oxide crystallites formed are certainly too low to be detected by XRD.

\section{Discussion}

The alteration of pigments can affect the resulting color of porcelain glazes through three mechanisms: reaction between a pigment and a glaze to form a different crystal with different 
color properties, extraction of an element from the pigment giving a crystal with different color properties, substitution of one element for another improving the stability of the crystal and, possibly, altering the color.[14] For the g-spinel and g-corundum, color alteration can be related to the second case: the extraction of $\mathrm{Al}$ from the pigment to the silicate melt, leaving Cr-enriched phases, $\mathrm{ZnAl}_{0.54} \mathrm{Cr}_{1.46} \mathrm{O}_{4}$ for g-spinel and $\mathrm{Cr}_{2} \mathrm{O}_{3}$ for g-corundum. It explains the color change from pink to brown (g-spinel) or green (g-corundum).

The mobility of $\mathrm{Al}$ is promoted by the chemical composition of the melt. The initial uncolored frit gives mainly a calcium aluminosilicate melt/glass after melting. In this type of glass, calcium cations ensure charge compensation of $\left(\mathrm{AlO}_{4}\right)^{-}$tetrahedra. The migration of $\mathrm{Al}$ from the grain of pigment to the melt is favored by the large amount of alkali or alkaline-earth cations in the melt, which are available for charge compensation. Indeed, the peraluminosity of the uncolored frit before the thermal treatment is equal to 0.50 , meaning that half of the alkali or alkaline-earth cations (mainly $\mathrm{Ca}^{2+}$ ) can be used to stabilize $\mathrm{Al}$ in tetrahedral environment. For g-corundum, there is a clear correlation between $\mathrm{Al}$ and $\mathrm{Ca}$ elemental maps in Fig. 6 indicating that the outward diffusion of $\mathrm{Al}$ into the glaze is due to the high $\mathrm{Ca}$ mobility towards the interface to provide charge compensation for $\mathrm{Al}^{3+}$. The crystal dissolution is then due to two processes: reaction at the melt/pigment interface to allow the release of $\mathrm{Al}$ cations and diffusion of $\mathrm{Ca}^{2+}$ cations in the melt towards the interface. Usually, diffusion is the rate-determining parameter controlling the crystal dissolution.

The migration of $\mathrm{Al}$ from the pigment to the melt increases locally its concentration around the pigment. As a consequence of the $\mathrm{Al}$ rich layer near the melt/pigment interface, the system can pass through the stability field of anorthite in the ternary $\mathrm{SiO}_{2}-\mathrm{Al}_{2} \mathrm{O}_{3}-\mathrm{CaO}[21,22]$. Furthermore, anorthite is known to crystallize without nucleating agent in $\mathrm{SiO}_{2}-\mathrm{Al}_{2} \mathrm{O}_{3}-\mathrm{CaO}-$ $\mathrm{MgO}$ glass system [23,24]. Al saturation concentration around some grains of pigment 
enables the formation of anorthite as firing at $1280^{\circ} \mathrm{C}$ is close to the maximum of crystal growth rate [25].

The formation of eskolaite in g-corundum indicates the poor solubility of $\mathrm{Cr}^{3+}$ for this melt composition and at this temperature. This is also consistent with large difference in solubility of $\mathrm{Cr}$ in chromian spinel and coexisting basaltic lavas [26,27]. We can propose that the Al compositional difference between the initial pigment and the melt can act as a driving force for $\mathrm{Al}$ diffusion. This is consistent with the fact that the dissolution of pigments is lower if the compositional difference is lower [16]. In g-spinel, this driving force is still present. However, we can note a lower Zn-diffusion towards the glaze than for Al. This is consistent with the final spinel composition $\mathrm{ZnAl}_{0.54} \mathrm{Cr}_{1.46} \mathrm{O}_{4}$, which implies a larger extraction of $\mathrm{Al}^{3+}$ cations than $\mathrm{Zn}^{2+}$ cations from the pigment to the silicate melt. It can be explained by the difference in the stability of various cations in the sites of the spinel lattice. Indeed, $\mathrm{Zn}$ is known to be the most stable of all ions in tetrahedral site in spinels [28]. Conversely, the octahedral sitepreference is higher for $\mathrm{Cr}^{3+}$ than for $\mathrm{Al}^{3+}$. As shown in Fig. 3, for g-spinel, the parent spinelCr0.41 grain and the new Cr-enriched phase spinel-Cr1.46 crystal exhibit the same crystallographic orientation. Therefore, the orientation of the crystals remains the same when Al migrates in the silicate melt. This result is consistent with the fact that spinel-Cr1.46 originates from the same grain of pigment.

While all aluminium cations migrate in the melt for g-corundum, only $66 \%$ of the $\mathrm{Al}$ initial amount present in the grain of pigment migrates in the melt for g-spinel (calculated using the chemical composition of the initial and final phases in g-spinel, respectively $\mathrm{ZnAl}_{1.59} \mathrm{Cr}_{0.41} \mathrm{O}_{4}$ and $\left.\mathrm{ZnAl}_{0.54} \mathrm{Cr}_{1.46} \mathrm{O}_{4}\right)$. $\mathrm{Al}$ migration is then limited by the presence of $\mathrm{Zn}$ and/or the crystalline structure. Firstly, this difference has an impact on the size of the resulting phases: sizes of $\mathrm{ZnAl}_{0.54} \mathrm{Cr}_{1.46} \mathrm{O}_{4}$ grains distribute between $200 \mathrm{~nm}$ and $1 \mu \mathrm{m}$, while the size of $\mathrm{Cr}_{2} \mathrm{O}_{3}$ is about $50 \mathrm{~nm}$. Secondly, this difference explains the larger quantity of anorthite formed in glaze g- 
corundum than in glaze g-spinel. Indeed, while anorthite is forming a continuous layer between the pigment and the glass in g-corundum, it only crystallizes in particular directions in g-spinel.

Every grains of pigment react during firing. However, they do not all have the same aspect in the resulting glaze (Fig.1). Indeed, while some grains are completely altered (Fig. 1a), others still contain the initial phase (Fig. 1b). This observation shows that the alteration process rate, and therefore the diffusion rate of $\mathrm{Al}$, is not the same for every grain of pigment. Al diffusion is strongly dependent on the initial grain size and on possible aggregation of grains (such as Fig. 1c). As the convection is limited into the glaze, which can be deduced from the important presence of bubbles [16], a local saturation composition of $\mathrm{Al}$ occurs preventing further outward diffusion of $\mathrm{Al}$ from the pigment, which in turn limit the pigment dissolution rate. Diffusion affecting the interface composition is again controlling the dissolution process.

Based on the different observations made, we try to reconstruct the sequence of alteration of different grains of pigment, explaining the variety of morphology encountered (Fig. 8). When Al migration is favored, the grain of pigment completely reacts with the silicate melt and is totally replaced by the Cr-enriched phase (sequence A2 to A4 in Fig. 8). When Al diffusion is limited, the duration of firing of the glaze does not allow the alteration process to reach the center of the grain (sequence B2 and B3 in Fig. 8). When the silicate melt around the pigment is saturated in $\mathrm{Al}$, crystallization of anorthite occurs, when the glaze is cooling down (scenario (i)), or when the glaze in heating up (scenario (ii)). Both scenarios result in the presence of partially reacted grains of pigment, surrounded by anorthite (step C4 in Fig. 8). The presence of anorthite is not important for coloration but implies an $\mathrm{Al}$ boundary rich layer that can prevent the crystal dissolution and thus the color change. 
Al diffusion appears to be a key parameter to understand the three different kind of population in glaze g-spinel. It is most likely that the three same populations can be observed under a SEM in glaze g-corrundum if the chemical contrast between the pigment and the uncolored frit was not too low. The three kind of grain observed (A, B and C) can be seen at different step of the alteration of the pigment. When $1280^{\circ} \mathrm{C}$ is maintained during 20 hours, every grains of pigment have the aspect of grain A in the glaze. This means that eventually, B and C evolve towards $\mathrm{A}$ if the firing process is long enough to complete the alteration of the pigment.

\section{Conclusion}

To better identify the sequence of reactions leading to the alteration of the color of two pigments (spinel $\mathrm{ZnAl}_{1.59} \mathrm{Cr}_{0.41} \mathrm{O}_{4}$ and corundum $\mathrm{Al}_{0.9} \mathrm{Cr}_{0.1} \mathrm{O}_{3}$ ) during firing of glazes, samples were analyzed down to the nanoscale. A common mechanism explains the color change, occurring as a result of the formation of a Cr-enriched phase with the same crystalline structure than the initial pigment. The Cr-enriched phase results from gradual diffusion of $\mathrm{Al}$ from the pigment toward the silicate melt during firing. The diffusion's rate of $\mathrm{Al}$ in the silicate melt is not the same for every grain of pigment and strongly depends on the environment of the grain. The crystallization of anorthite confirms the hypothesis that $\mathrm{Al}$ migrates from the grain of pigment to the silicate melt.

\section{Acknowledgements}

This work was supported by the Réseau Francilien sur les oxydes fonctionnels (DIM Oxymore) and the Région Ile-de-France. L. Verger acknowledges C. Bouttaz for her expertise 
in the preparation of the samples. The purchase of the Scanning Electron Microscope (SEM) facility of the Institut de Minéralogie, de Physique des Matériaux et de Cosmochimie (IMPMC) was supported by Région Ile de France grant SESAME 2006 nI-07-593/R, INSUCNRS, INP-CNRS, University Pierre et Marie Curie - Paris 6, and by the French National Research Agency (ANR) grant no. ANR-07-BLAN-0124-01.

\section{References}

[1] A.R. Cooper, W.D. Kingery, Dissolution in Ceramic Systems: I, Molecular Diffusion, Natural Convection, and Forced Convection Studies of Sapphire Dissolution in Calcium Aluminum Silicate, J. Am. Ceram. Soc. 47 (1964) 37-43. doi:10.1111/j.11512916.1964.tb14638.x.

[2] P.L. Roeder, I. Reynolds, Crystallization of Chromite and Chromium Solubility in Basaltic Melts, J. Petrol. 32 (1991) 909-934. doi:10.1093/petrology/32.5.909.

[3] A.J. Irving, A review of experimental studies of crystal/liquid trace element partitioning, Geochim. Cosmochim. Acta. 42 (1978) 743-770. doi:10.1016/0016-7037(78)90091-1.

[4] P. Hrma, J.D. Vienna, B.K. Wilson, T.J. Plaisted, S.M. Heald, Chromium phase behavior in a multi-component borosilicate glass melt, J. Non-Cryst. Solids. 352 (2006) 2114-2122. doi:10.1016/j.jnoncrysol.2006.02.051.

[5] M. Martos, M. Martínez, E. Cordoncillo, P. Escribano, Towards more ecological ceramic pigments: Study of the influence of glass composition on the colour stability of a pink chromium-doped ceramic pigment, J. Eur. Ceram. Soc. 27 (2007) 4561-4567.

[6] S. Mestre, M.P. Gómez-Tena, M.F. Gazulla, A. Gozalbo, Interaction of the chromiumiron black pigment with porcelanised stoneware, Ceram. Int. 39 (2013) 7453-7459. doi:10.1016/j.ceramint.2013.02.090.

[7] S.H. Murdock, R.A. Eppler, The interaction of ceramic pigments with glazes, Am. Ceram. Soc. Bull. 68 (n.d.) 77-78.

[8] N.L. Vauquelin, Mémoire sur la découverte d'un nouveau métal à l'état d'acide et d'oxide dans le plomb rouge de Sibérie, le rubis et l'émeraude, et d'une nouvelle terre dans l'émeraude et le béril, Journal de la Société des pharmaciens de Paris, anVI (1797) 174-176.

[9] A. Brongniart, Traité des arts céramiques ou des poteries: considérées dans leur histoire, leur pratique et leur théorie, Béchet jeune, 1854.

[10] E. Cordoncillo, F. del Río, J. Carda, M. Llusar, P. Escribano, Influence of some mineralizers in the synthesis of sphene-pink pigments, J. Eur. Ceram. Soc. 18 (1998) $1115-1120$.

[11] H. Yurdakul, S. Turan, E. Ozel, The mechanism for the colour change of iron chromium black pigments in glazes through transmission electron microscopy techniques, Dyes Pigments. 91 (2011) 126-133.

[12] E. Ozel, S. Turan, Production and characterisation of iron-chromium pigments and their interactions with transparent glazes, J. Eur. Ceram. Soc. 23 (2003) 2097-2104. 
[13] S. Ahmadi, A. Aghaei, B. Eftekhari Yekta, Synthesis of $\mathrm{Y}(\mathrm{Al}, \mathrm{Cr}) \mathrm{O}_{3}$ red pigments by coprecipitation method and their interactions with glazes, Ceram. Int. 35 (2009) 34853488. doi:10.1016/j.ceramint.2009.04.029.

[14] D.R. Eppler, R.A. Eppler, The relative stability of ceramic pigments, Mater. Equip.Whitewares Ceram. Eng. Sci. Proc. Vol. 18. 18 (2009) 139.

[15] V. Harisanov, R.. Pavlov, I.. Marinova, V. Kozhukharov, J.. Carda, Influence of crystallinity on chromatic parameters of enamels coloured with malayaite pink pigments, J. Eur. Ceram. Soc. 23 (2003) 429-435.

[16] L. Verger, O. Dargaud, G. Rousse, M. Cotte, L. Cormier, The stability of gahnite doped with chromium pigments in glazes from the French manufacture of Sèvres, J. Am. Ceram. Soc. (2016) doi: 10.1111/jace.14452.

[17] C.J. Byrne, S.G. Kutney, R.A. Pipoly, How glaze composition affects chrome-tin pinks, Am. Ceram. Soc. Bull. 73 (1994) 46-49.

[18] L. Verger, O. Dargaud, G. Rousse, E. Rozsályi, A. Juhin, D. Cabaret, M. Cotte, P. Glatzel, L. Cormier, Spectroscopic properties of $\mathrm{Cr}^{3+}$ in the spinel solid solution $\mathrm{ZnAl}_{2-}$ ${ }_{x} \mathrm{Cr}_{\mathrm{x}} \mathrm{O}_{4}$, Phys. Chem. Miner. 43 (2015) 33-42. doi:10.1007/s00269-015-0771-8.

[19] L.R. Rossi, W.G. Lawrence, Elastic Properties of Oxide Solid Solutions: The System $\mathrm{Al}_{2} \mathrm{O}_{3}-\mathrm{Cr}_{2} \mathrm{O}_{3}$, J. Am. Ceram. Soc. 53 (1970) 604-608.

[20] H. Xu, P.R. Buseck, M.A. Carpenter, Twinning in synthetic anorthite; a transmission electron microscopy investigation, Am. Mineral. 82 (1997) 125-130. doi:10.2138/am1997-1-214.

[21] E.M. Levin, C.R. Robbins, H.F. McMurdie, Phase diagrams for ceramists, The American Ceramic Society, 1964.

[22] P. Richet, M. Roskosz, J. Roux, Glass formation in silicates: Insights from composition, Chem. Geol. 225 (2006) 388-401.

[23] C.L. Lo, J.G. Duh, B.S. Chiou, Low temperature sintering and crystallisation behaviour of low loss anorthite-based glass-ceramics, J. Mater. Sci. 38 (n.d.) 693-698. doi:10.1023/A:1021836326089.

[24] C. Leonelli, T. Manfredini, M. Paganelli, P. Pozzi, G.C. Pellacani, Crystallization of some anorthite-diopside glass precursors, J. Mater. Sci. 26 (1991) 5041-5046. doi:10.1007/BF00549889.

[25] L. Klein, D.R. Uhlmann, Crystallization behavior of anorthite, J. Geophys. Res. 79 (1974) 4869-4874. doi:10.1029/JB079i032p04869.

[26] S.J. Barnes, P.L. Roeder, The Range of Spinel Compositions in Terrestrial Mafic and Ultramafic Rocks, J. Petrol. 42 (2001) 2279-2302.

[27] C.H. Wijbrans, S. Klemme, J. Berndt, C. Vollmer, Experimental determination of trace element partition coefficients between spinel and silicate melt: the influence of chemical composition and oxygen fugacity, Contrib. Mineral. Petrol. 169 (2015) 45. doi:10.1007/s00410-015-1128-5.

[28] A. Miller, Distribution of Cations in Spinels, J. Appl. Phys. 30 (1959) S24. doi:10.1063/1.2185913. 

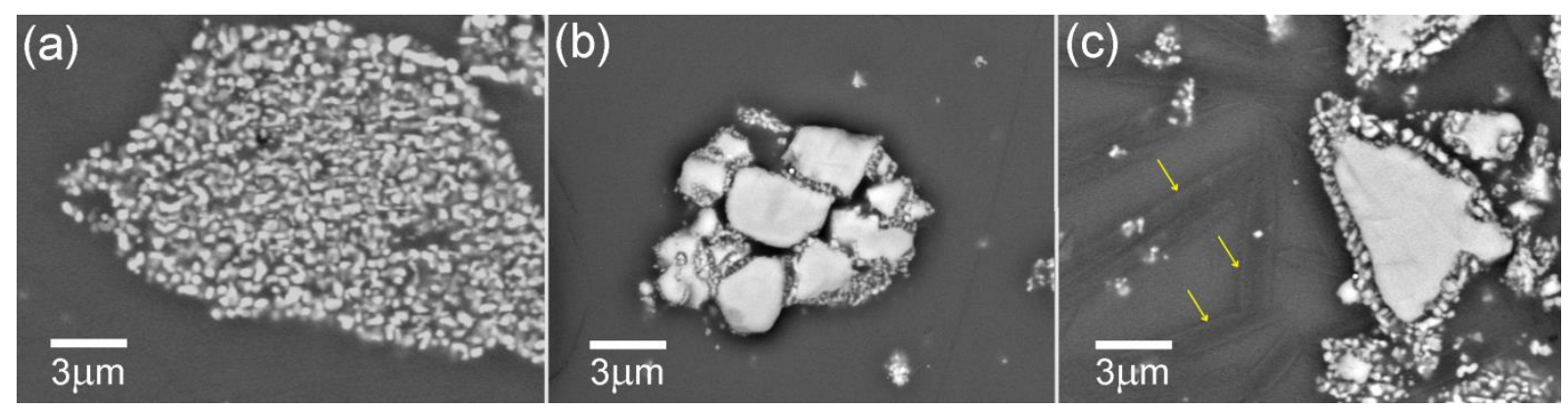

Fig.1. SEM images of three different grains of pigments in g-spinel glaze, illustrating different reactions of the pigment in the glaze (signal: ASB, EHT $=15 \mathrm{kV}$ ) : (a) a completely altered grain, composed of spinel-Cr1.46; (b) a partially altered grain, with pristine spinelCr0.41 in the centre and spinel-Cr1.46 in the periphery; (c) aggregate of partially altered grains with additional phases indicated by arrows. 


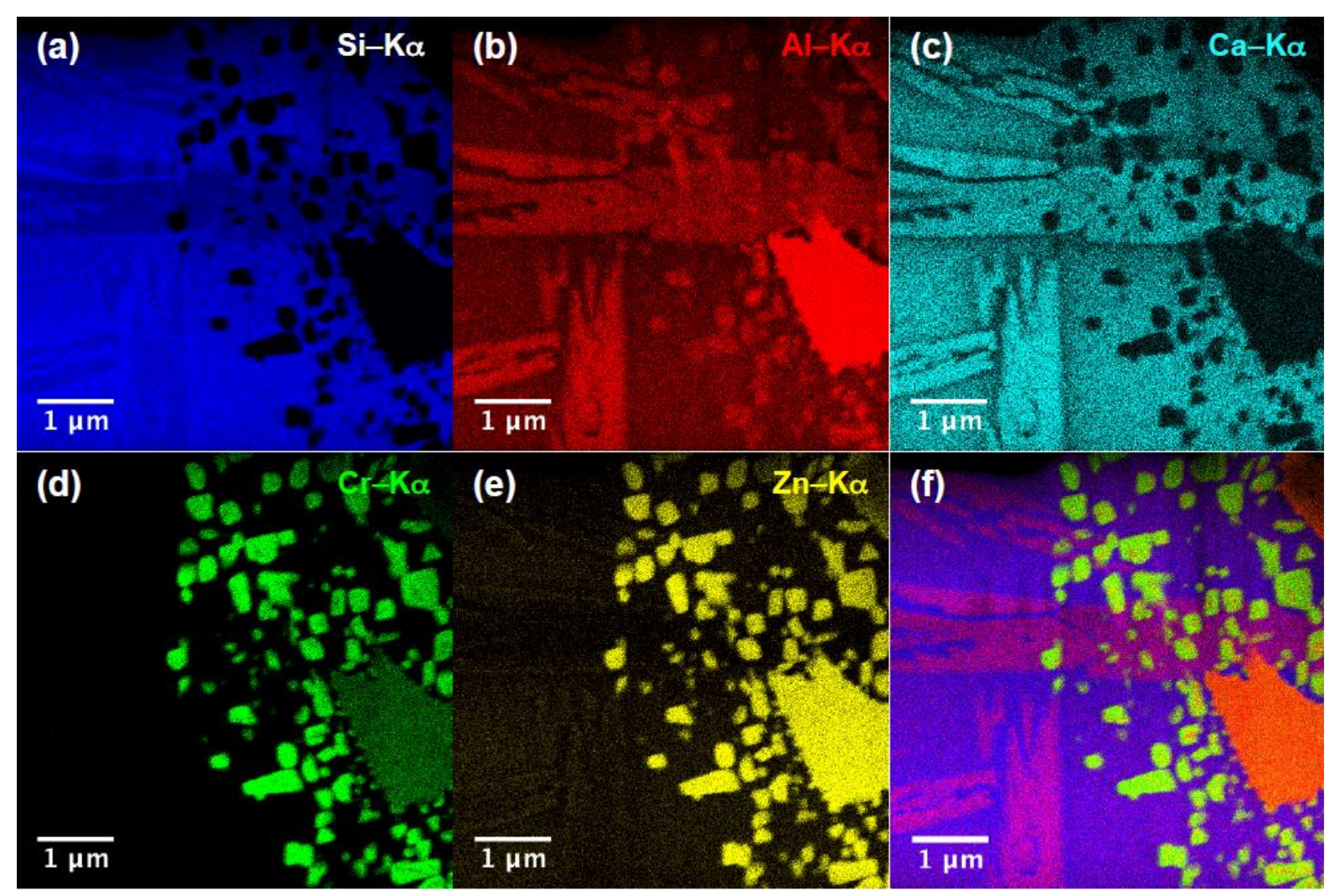

Fig.2: elemental XEDS maps of g-spinel sample. (a-e) STEM-XEDS elemental mapping acquired using energy windows related respectively to $\mathrm{Si}-\mathrm{K} \alpha, \mathrm{Al}-\mathrm{K} \alpha, \mathrm{Ca}-\mathrm{K} \alpha, \mathrm{Cr}-\mathrm{K} \alpha, \mathrm{Zn}-\mathrm{K} \alpha$ lines. (f) Composite image build with $\mathrm{Al}, \mathrm{Cr}$ and $\mathrm{Si}$ elemental maps. Orange area corresponds to pristine spinel-Cr0.41, bright green areas correspond to $\mathrm{Cr}$-rich spinel crystals, violet areas correspond to $\mathrm{SiO}_{2}$-rich glass and magenta regions are related to an anorthite phase.

Elemental maps are not quantitative (not background corrected). 


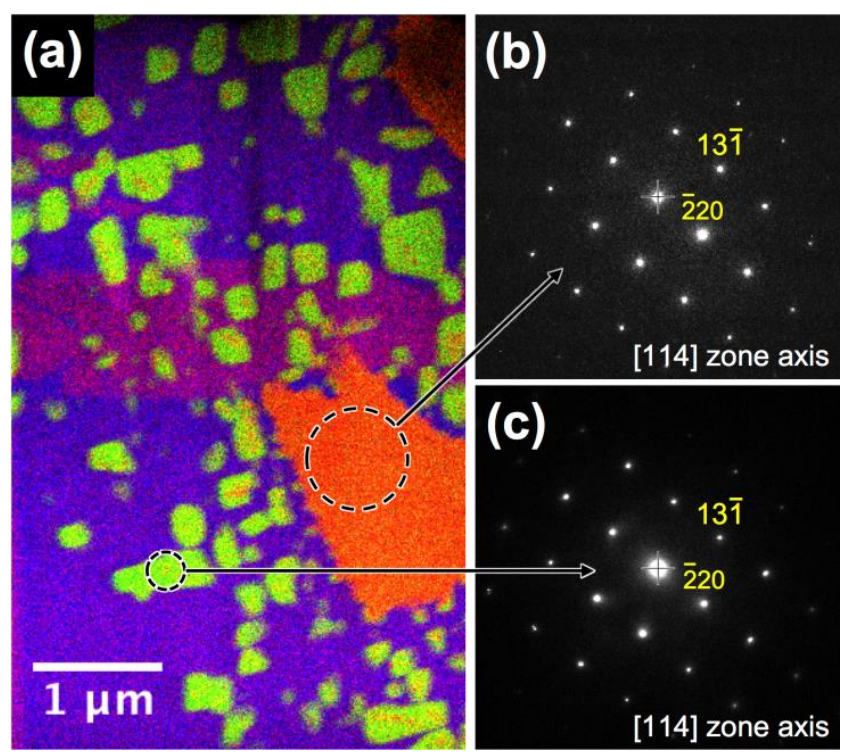

Fig.3: Orientational relationships between spinel-Cr0.4 and spinel-Cr1.46. (a) STEMXEDS image of the initial pigment (spinel-Cr0.41, appearing in orange) surrounded by $\mathrm{Cr}$ rich smaller grains (spinel-Cr1.46, appearing in bright green). (b) and (c) Selecting area electron diffraction (SAED) patterns corresponding to the areas indicated in (a). These [114] zone axis SAED patterns are related one to each other by tilting smaller than 2 deg indicating a very close orientational relationships between the pristine grain and the $\mathrm{Cr}$-rich phases. 

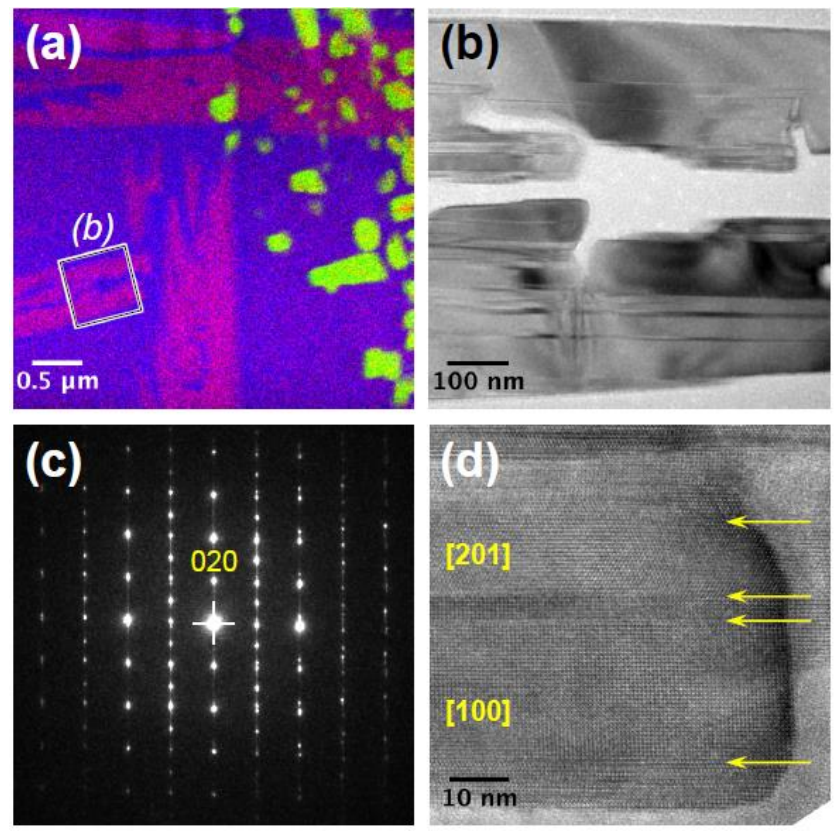

Fig.4: analyses of Si-rich phases. (a) composite image build with $\mathrm{Al}, \mathrm{Cr}$ and $\mathrm{Si}$ elemental maps (zoom of Fig. 2f). Violet areas correspond to a $\mathrm{SiO}_{2}$-rich glass and magenta regions are related to an anorthite phase. (b) TEM bright field image related to the area labeled (b) in (a) and corresponding SAED pattern(c). (d) HREM image of an anorthite phase related to the magenta areas exhibiting typical features i.e. planar stacking fault and (010) twinning planes as reported by $\mathrm{Xu}$ et al. [20]. 


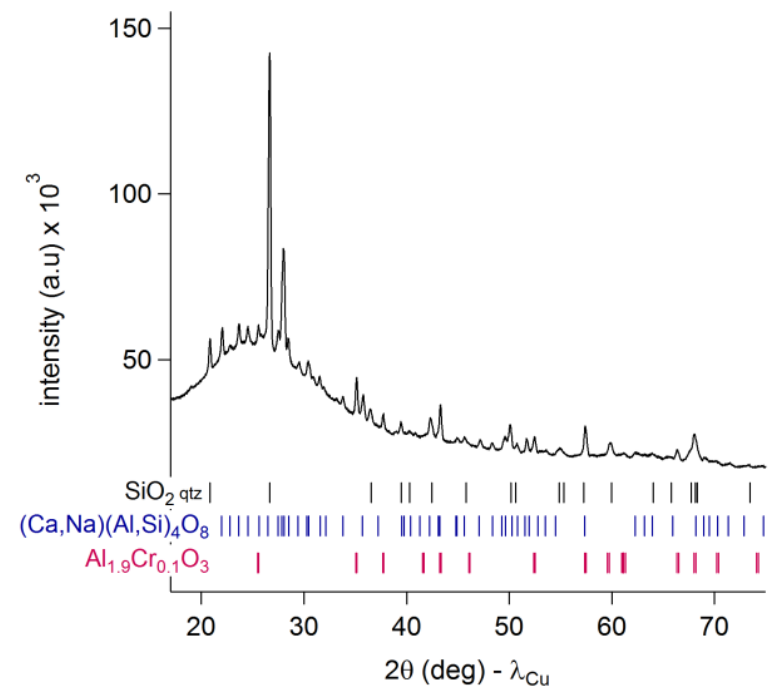

Fig.5: XRD pattern of the sample g-corundum. Quartz $\mathrm{SiO}_{2}$ and $(\mathrm{Ca}, \mathrm{Na})(\mathrm{Si}, \mathrm{Al})_{4} \mathrm{O}_{8}$ were indexed according to the ICDD 00-005-0490 and ICDD 00-041-1481 files respectively. $\mathrm{Al}_{1.9} \mathrm{Cr}_{0.1} \mathrm{O}_{3}$ was indexed using the Rietveld refinement of pigment 10059. 


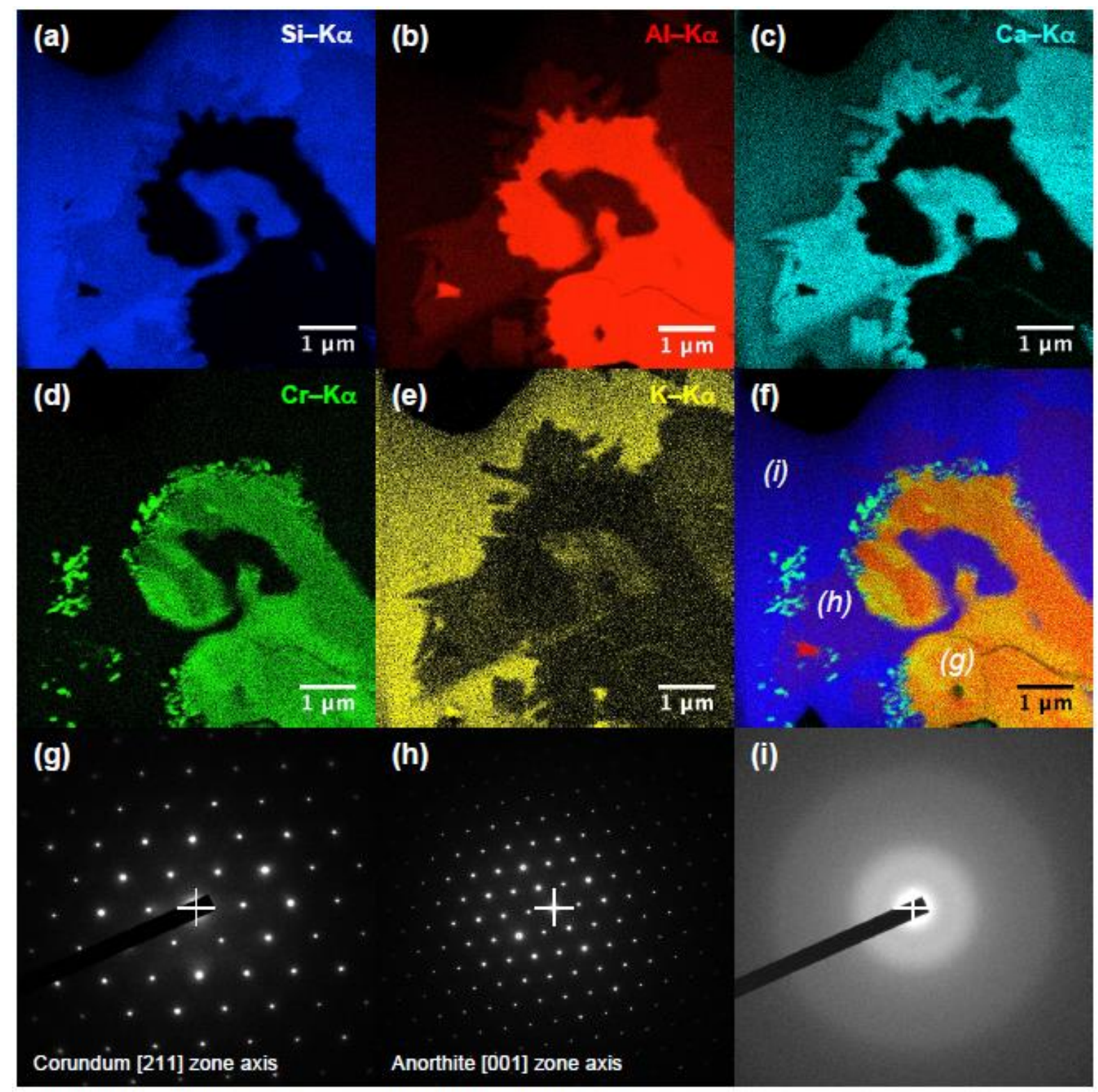

Figure 6: elemental XEDS maps of g-corundum sample. (a-e) STEM-XEDS elemental mapping acquired using energy windows related respectively to $\mathrm{Si}-\mathrm{K} \alpha, \mathrm{Al}-\mathrm{K} \alpha, \mathrm{Ca}-\mathrm{K} \alpha, \mathrm{Cr}$ $\mathrm{K} \alpha, \mathrm{K}-\mathrm{K} \alpha$ lines. (f) Composite image build with $\mathrm{Al}, \mathrm{Cr}$ and $\mathrm{Si}$ elemental maps. Orange area labeled $(g)$ corresponds to pristine $\mathrm{Al}_{1.9} \mathrm{Cr}_{0.1} \mathrm{O}_{3}$ with corundum structure, small bright green areas correspond to $\mathrm{Cr}_{2} \mathrm{O}_{3}$ eskolaite crystals, blue area labeled (i) correspond to a glass and dark blue area labeled $(h)$ correspond to anorthite phase. (g-i) SAED patterns corresponding respectively to corundum (g), anorthite (h) and the amorphous phase (i). 

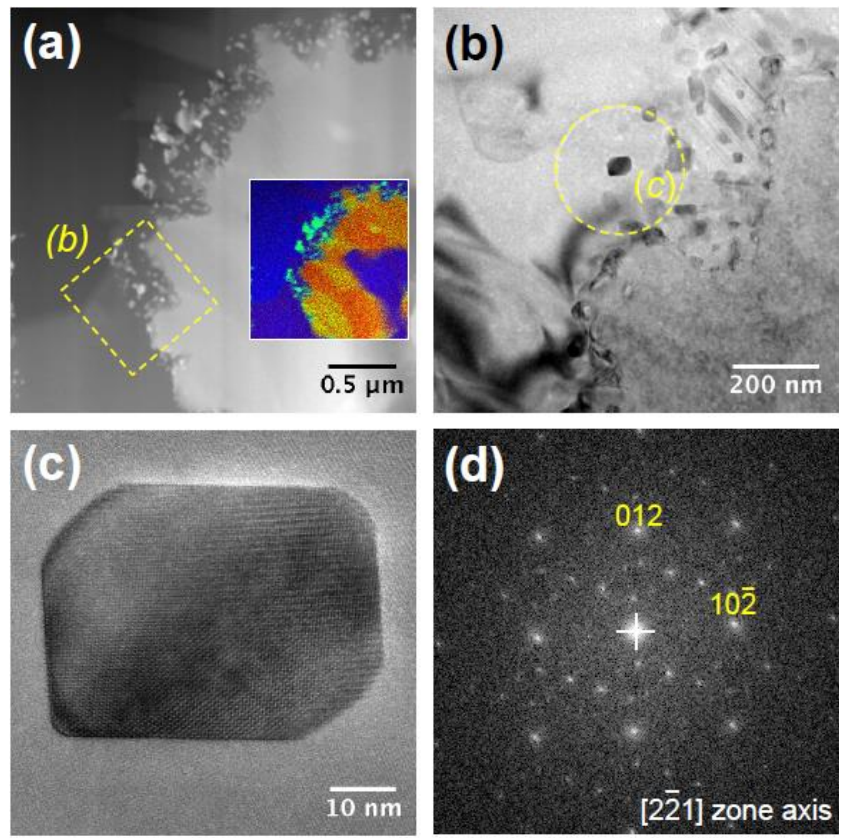

Fig. 7: identification of small $\mathrm{Cr}_{2} \mathrm{O}_{3}$ crystals

(a) STEM-HAADF image of the large $\mathrm{Al}_{1.9} \mathrm{Cr}_{0.1} \mathrm{O}_{3}$ single crystal boundary. The corresponding STEM-XEDS composite image is shown in insert. (b) TEM bright field image of the area labeled (b) in (a). Many small $\mathrm{Cr}_{2} \mathrm{O}_{3}$ crystals are visible in the vicinity of the interface between pristine $\mathrm{Al}_{1.9} \mathrm{Cr}_{0.1} \mathrm{O}_{3}$ crystal and the anorthite phase. (c) HREM image of the $\mathrm{Cr}_{2} \mathrm{O}_{3}$ crystal within the area labeled (c) in (b). (d) The corresponding FFT pattern is indexed according to the [2 $\overline{2} 1]$ zone axis of the eskolaite structure. Weak additional reflections are due to the surrounding anorthite phase. 


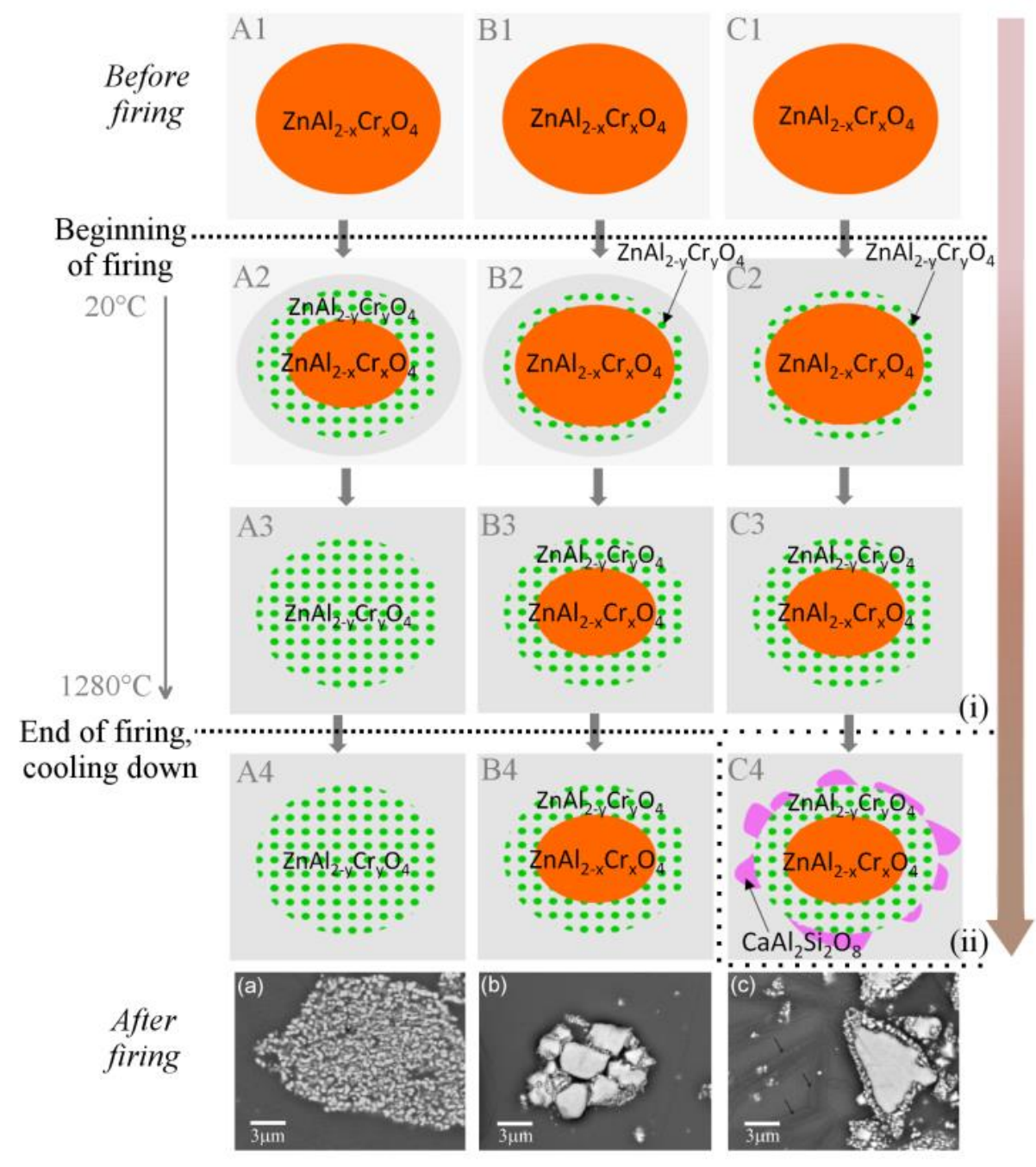

Fig.8: Proposed model for the reactivity of $\mathrm{ZnAl}_{2-\mathrm{x}} \mathrm{Cr}_{\mathrm{x}} \mathrm{O}_{4}$ type pigment in silicate melt with low $R . \mathrm{Al}$ is gradually migrating from the grain of pigment in the silicate melt leading to the formation of a Cr-enriched phase $\mathrm{ZnAl}_{2-\mathrm{y}} \mathrm{Cr}_{\mathrm{y}} \mathrm{O}_{4}$. The arrow on the right corresponds to the resulting color of the sample, calculated from the UV-visible reflectance spectra of samples fired at different temperature along the firing curve. 